\title{
Ultrasound Guidance Is Helpful for Paravertebral Block Performance and Catheter Placement in Patients with Laminectomy after Thoracotomy or Lumbotomy: A Case Series Imaging Study
}

\author{
Pierre Pandin $^{1}$, Samia Rettab ${ }^{2}$, Alphonse Lubansu ${ }^{3}$ \\ ${ }^{1}$ Department of Anesthesiology and Intensive Care, Clinic Orthopaedy and Traumatology, Neurosurgery \& ENT CUB Erasmus Hos- \\ pital, Free University of Brussels, Brussels, Belgium; ${ }^{2}$ Department of Anesthesiology and Intensive Care, CUB Erasmus Hospital, Free \\ University of Brussels, Brussels, Belgium; ${ }^{3}$ Department of Neurosurgery, CUB Erasmus Hospital, Free University of Brussels, \\ Brussels, Belgium. \\ Email: ppandin@ulb.ac.be
}

Received January $16^{\text {th }}, 2013$; revised February $20^{\text {th }}, 2013$; accepted February $28^{\text {th }}, 2013$

\begin{abstract}
Today, the ultrasound guidance (USG) in regional anesthesia is gold standard more and more often used for medial or paramedian approaches around to the spine, such as the paravertebral (PV) block. Local anatomical changes may greatly handicap the performance of this type of block. We present clinical, sonographic, and radiological data on successful PV block and catheter placement in four patients with vertebral diseases, targeting thoracotomy or lumbotomy postoperative pain after stabilization of the involved vertebral body and preliminary arthrodesis with laminectomy by the posterior approach. We emphasize the importance of USG in this special context involving local anatomical disturbance.
\end{abstract}

Keywords: Block; Catheter; Guidance; Laminectomy; Lumbotomy; Paravertebral; Thoracotomy; Ultrasound

\section{Introduction}

Whatever the etiology (trauma, tumor, infections), spine arthrodesis surgery includes complex and combined procedures on the anterior and posterior vertebral structures for long-term stabilization. To achieve this goal, when the vertebral body must be consolidated or replaced, the surgeon may use anterior, antero-lateral, or postero-lateral approaches by thoracotomy or lumbotomy after a preliminary posterior fixation. Although the postoperative pain of posterior fixation may be relatively easily controlled using standard general analgesia (opiates, nonsteroidal anti-inflammatory agents, paracetamol, or acetaminophen), pain control after a thoracotomy or a lumbotomy requires more systematically polymodal analgesia, including a regional anesthesia technique (paravertebral (PV) vs epidural block) to allow more comfortable and efficient respiratory physiotherapy for better recovery of pulmonary function and to decrease the incidence of possible lung complications [1-3]. The safe and efficient performance of these techniques is based on identification of local anatomical landmarks like the transverse processes $[4,5]$. Nevertheless, a laminectomy or the in- sertion of pedicle screws can interfere with these landmarks and may even contraindicate regional anesthesia. Ultrasound guidance (USG) has already been successfully investigated in normal local anatomy $[6,10]$ and could be an answer to this problem, giving the opportunity to identify the appropriate entry point with accuracy in the context of reconfigured local anatomy. We have sought to demonstrate the benefits of USG in the four cases presented here of PV blocks with catheter insertion, providing at the same time detailed technical descriptions and illustrative ultrasound (US) pictures, correlating them with the individual results of the postoperative assessment of the efficacy of the corresponding PV blocks.

\section{Case Series}

Two days to one week before the USG procedure, all patients were operated by the posterior approach for intervertebral stabilization with laminectomy and posterior arthrodesis using vertebral pedicle screws. Table 1 summarizes the general patient information and medical history. At that time, no problems with postoperative pain-control occurred (the 0 to $100 \mathrm{~mm}$ visual analogue scale scores 
Table 1. Summary of the anesthesia and surgery for each patient.

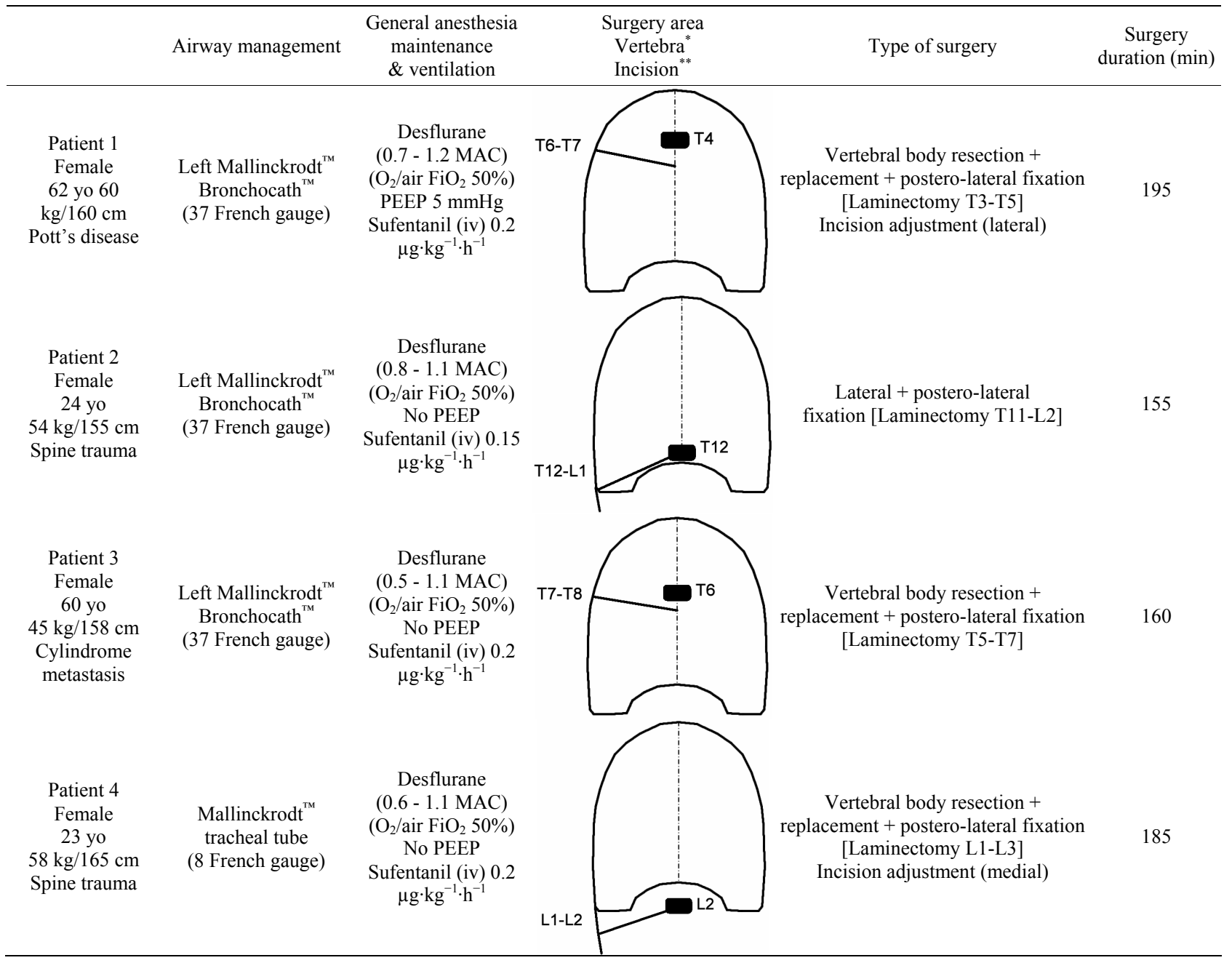

*The pathological vertebra operated (as a black rectangle) first for laminectomy (posterior approach) and second for corporectomy with prosthetic replacement by antero-lateral approach using a postero-lateral thoracotomy. ${ }^{* *}$ The side and level of the postero-lateral thoracotomy or lumbotomy (as an oblique straight black line).

were always less than $50 \mathrm{~mm}$ during a standardized and systematic follow-up at postoperative day 3 . For the second surgical period, a need for optimal postoperative pain control after either the thoracotomy or lumbotomy (on the right side) led us to plan to perform a regional block with a catheter placement for continuous infusion of local anesthetic agent, complementary to general i.v. analgesia [3]. After discussion with the surgeon, we decided to perform the block only after the surgery to avoid the risk that a catheter could rise into the surgical field after a possible enlargement of the surgical incision, which is often required in such procedures. After collegial discussion, the theoretical positive ratio "analgesic advantage" against "infection risk" led the surgeon to accept the insertion of a catheter just below the surgical area. Consequently, because PV performance has been reported to be less risky in the anesthetized patient [11], we performed the PV block just after the surgery ended, when each patient had recovered efficient spontaneous breathing (e.g., respiratory rate $>8 \mathrm{~min}^{-1}$, pulse oximetry $>95 \%$ for $\mathrm{FiO}_{2} 50 \%$, and end-tidal $\mathrm{CO}_{2}<45 \mathrm{mmHg}$ without spontaneous pressure-assisted ventilation). The catheter in the lateral decubitus position before the patient emerged from general anesthesia (Figure 1). Table 1 also provides information about each patient's perioperative period. General anesthesia was always maintained with desflurane (Suprane ${ }^{\mathrm{TM}}$, Baxter Belgium ${ }^{\mathrm{TM}}$, Brussels, Belgium). No perioperative incident and no postoperative complications were noted.

First, a radiograph (Exposcope $8000^{\mathrm{TM}}$ Ziehm Imaging $^{\text {TM }} \mathrm{GmbH}$, Nuremberg, Germany) was taken to identify the cutaneous projection of the insertion point of the needle into the right PV area of each patient, at the level just below the lower end of the laminectomy (Figure 1). 
After that, a 180 Plus $^{\mathrm{TM}}$ US machine (Sonosite $^{\mathrm{TM}}$, Bothell, WA, USA) with a $10-5 \mathrm{MHz} 38 \mathrm{~mm}$ broadband linear array transducer (depth between 5 to $7 \mathrm{~cm}$ ) set in "General" imaging mode was used for the preliminary US pinpointing followed by the needle insertion and the catheter placement. Table 2 details the features of each block.

Only about the scan, similarly to Ben-Ari et al. [7], we performed a careful short-axis and long-axis scanning, but with the slight modification that we began medially to the thoracic, thoraco-lumbar, or lumbar PV areas of each patient and only on the right side in our cases. In the context of important local anatomical modifications induced by the surgery, it seemed to us easier to identify medial normal structures (mainly spine midline with the spinous processes) and based on that, to move the transducer 4 to $5 \mathrm{~cm}$ laterally to pinpoint the respective PV areas, vertebral and intervertebral level by level. Consequently, in each patient, we started with the short-axis scanning from two levels below to two levels above the pathological vertebra. This approach allowed us to study as accurately as possible the median and the paramedian (PV) anatomy below, above, and at the laminectomy level to determine the possible reconfiguring of the structures (mainly the PV area) due to the surgery. Then the probe was rotated to scan the same area longitudinally (long axis) to confirm the initial findings, particularly about the site of the laminectomy. Between two adjacent spinous processes, by toggling (tilting) the probe in every axis, the PV muscles (Figure 2) could be identified beside the vertebral structures not only in real time but also for the retrospective analysis of the sonograms.
Following this method, the PV area was always located in each patient without major difficulty (Table 2), particularly at the needle-insertion point preliminarily defined using X-ray (Figure 1), just at the end of the surgery, before to withdraw the mobile $\mathrm{C}$-arm system. The depth of location of the respective thoracic or lumbar nerve was carefully noted (Figure 2). In short-axis view, a $17-\mathrm{G}$ Tuohy needle (Epi Mini Set $17 \mathrm{G}^{\mathrm{TM}}$ Polymedic by Tenema $^{\mathrm{TM}}$, Carrière-sur-Seine, France) was inserted outof-plane immediately down and medial to the probe. The Tuohy needle was advanced point by point, in increments through the erector spinae (ES) muscle, aiming at the PV after having felt the click of the tip of the needle through the superior costotransverse ligament anterior to the muscle (Figure 2). After each advance, $0.2 \mathrm{ml}$ of normal saline was injected if necessary to make easier the tip of the needle location, until the PV was easily dilated (1 to $2 \mathrm{ml}$ ) on the sonogram.

Once the space was identified, the needle was disconnected from the normal saline syringe, and after a negative blood and air aspiration test, the local anesthetic mixture (Table 2) with $2 \mathrm{ml}$ of iodixanol $320 \mathrm{mg} \cdot \mathrm{ml}^{-1}$ (Visipaque $^{\mathrm{TM}}$, Amersham Health ${ }^{\mathrm{TM}}$, Diegem, Belgium) was injected. Then, a radiograph was taken for controlling the injection, followed by insertion of a $19-G$ polyethylene catheter $2-3 \mathrm{~cm}$ beyond the tip of the needle. In the recovery room, approximately 30 minutes after the block procedure, using a pinprick test with a $25-\mathrm{G}$ needle, we determined the number of dermatomes that were completely anesthetized (Table 2). The PV catheter was then connected to a pump $\left(\mathrm{Gemstar}^{\mathrm{TM}}{ }^{\mathrm{M}}\right.$, Hospira ${ }^{\mathrm{TM}}$, Lake
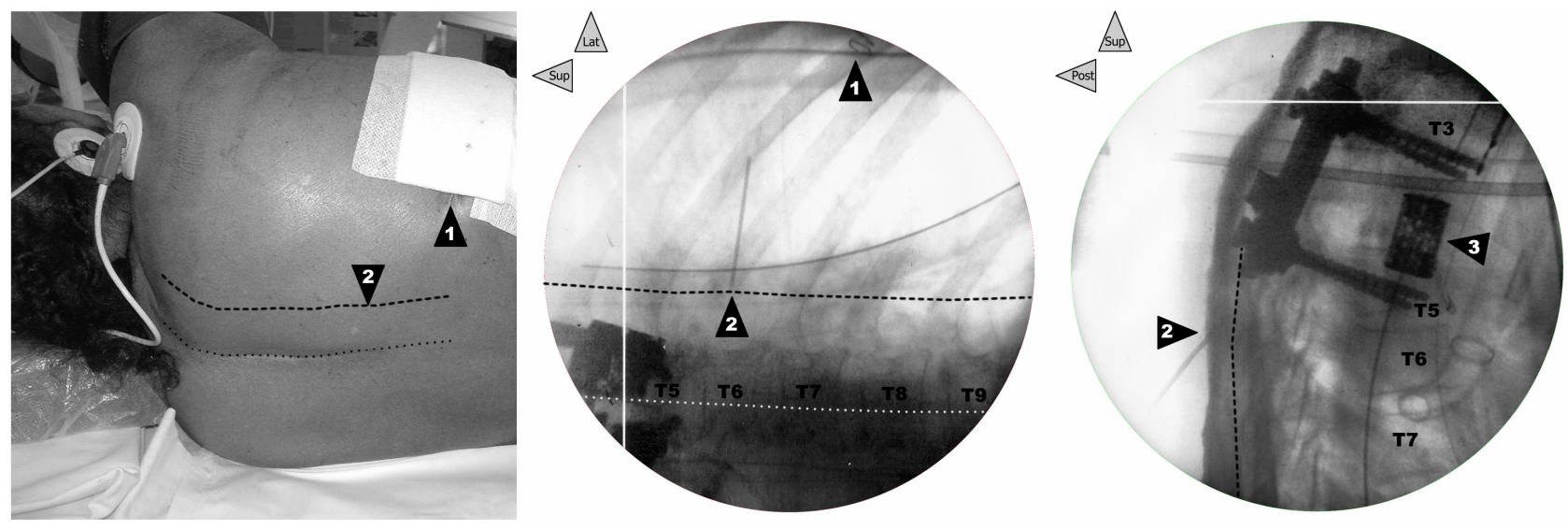

Figure 1. Correlation between clinical landmarks of the surface and X-rays. In patient 1, before the ultrasound preliminary examination, on left, cutaneous landmarks and in the middle and on right, face and profile radiographs, respectively (the legends are common to the three views): 1) Posterior end of the incision of the right T6-T7 thoracotomy (surgical staples on the frontal radiograph in the middle). While the dotted line draws the cutaneous projection of the supraspinous line (previous posterior approach for first laminectomy and second T3-T5 arthrodesis), the dashed line (3 cm lateral) marks the PV line. 2) T5-T6 right PV point for the needle insertion (in the middle, on the frontal radiograph, the internal end of a 20-G needle $3 \mathrm{~cm}$ in length allows localization of this needle-insertion site). 3) T4 corporeal vertebral prosthesis inserted after corporectomy during the second surgical period following an antero-lateral approach by postero-lateral right thoracotomy. 

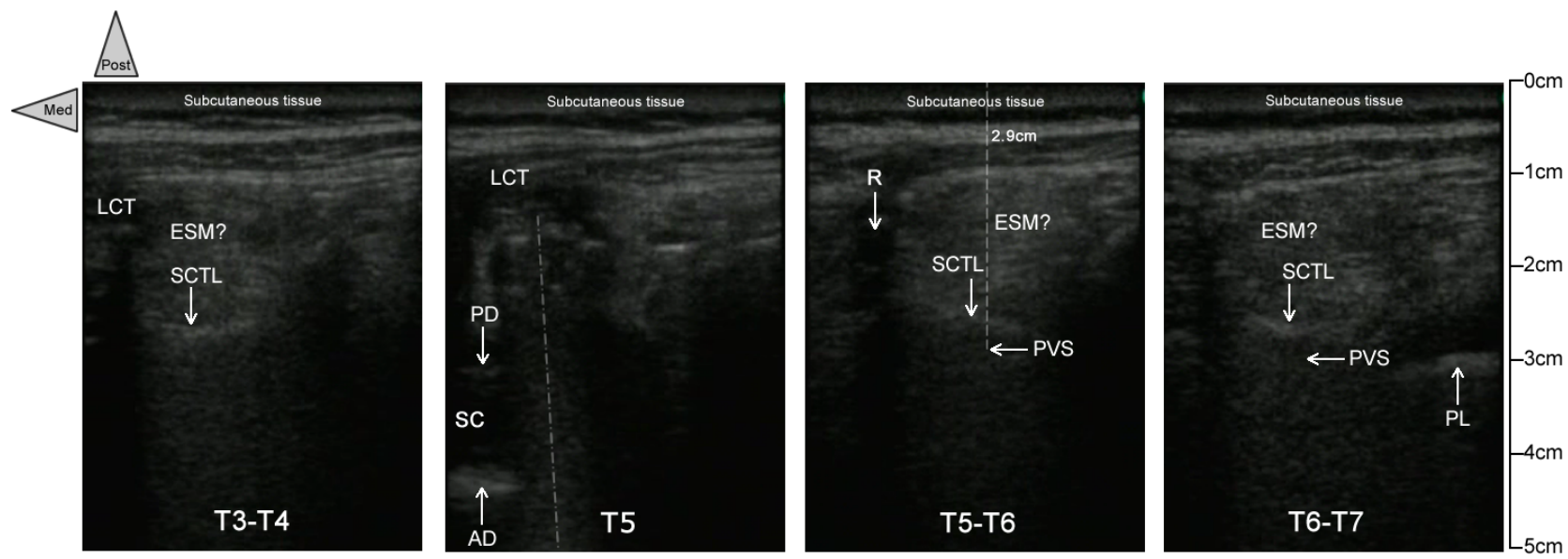

SCTL: superior costotransverse ligament; ESM: erector spinae muscle; LCT: local cicatricial tissue;

SC: spinal canal; AD: anterior dura; PD: sopterior dura; PVS: paravertebral space; PL: pleura.

Figure 2. Short-axis ultrasound pinpointing before the needle insertion. In patient 1 , the transverse sonograms of the right PV area with a $10-5 \mathrm{MHz} 38-\mathrm{mm}$ broadband linear array transducer (depth of $7 \mathrm{~cm}$ ) at, respectively, T3-T4 (on left), T5, T5-T6, and T6-T7 (on left). While the T5-T6 and T6-T7 views are similar, with the respective PV area located at $2.9 \mathrm{~cm}$ of depth, anterior to superior costotransverse ligament (with the same sort of shape), the PV area is clearly modified because of the right pedicle screw at the T5 level and the laminectomy at the T4 level, respectively. At T3-T4 (on right), the erectus spinae muscle seems more hypoechoic, heterogeneous, edematous, and less well delimited related to the surgical site, just below, but the superior costotransverse ligament is localizable once again without major changes.

Forest; IL, USA) to infuse $2 \mathrm{mg} \cdot \mathrm{ml}^{-1}$ ropivacaine (Table 2). As indicated in Table 2 , each patient additionally systematically received paracetamol $15 \mathrm{mg} \cdot \mathrm{kg} \cdot 6 \mathrm{~h}^{-1}$ (Perfusalgan $^{\mathrm{TM}}$, Bristol-Mayer Squibb SA ${ }^{\mathrm{TM}}$, Braine l'Alleud, Belgium) and diclofenac $1.2 \mathrm{mg} \cdot \mathrm{kg} \cdot 12 \mathrm{~h}^{-1}$ (Voltaren $^{\mathrm{TM}}$, Novartis Pharma SA ${ }^{\mathrm{TM}}$, Vilvoorde, Belgium), and only if needed, piritramide (Dipidolor ${ }^{\mathrm{TM}}$, Janssen Pharmaceutica $\mathrm{SA}^{\mathrm{TM}}$, Beerse, Belgium) i.v. $0.02 \mathrm{mg} \cdot \mathrm{kg} \cdot 1 \mathrm{~h}^{-1}$ maximum in the Post-Anesthesia Care Unit (PACU) vs im $0.15 \mathrm{mg} \cdot \mathrm{kg} \cdot 6 \mathrm{~h}^{-1}$ maximum in the bedroom, following the Acute Pain Service(APS) algorithm (two successive visual analogue scale scores $>30 \mathrm{~mm}$ with a time interval of 10 minutes in the PACU or 1 hour in the bedroom). All catheters were removed within 72 hours after the completion of surgery without any sign of infection.

\section{Discussion}

Until now, the published data [6-12] on USG catheterization has involved only patients with normal anatomy. Among the interesting recently published data [6-8,11, 12] are two methods to approach the PV area. While the classical approach $[6,8,12]$ transposes the usual technique $[4,5]$ relative to the USG approach, in the 3 to 4 $\mathrm{cm}$ lateral to the spine midline, the alternative corresponds to a retrograde intercostal approach that is more lateral $(8 \mathrm{~cm})$. Under the specific conditions described here (with a deep local redrafting after the preliminary laminectomy, Figures $\mathbf{2}$ and $\mathbf{3}$ ), the main concern was to determine with accuracy the persistence or not of the PV area in order to succeed in the catheterization technique for efficient postoperative pain control after the thoracotomy or the lumbotomy. For this reason, we selected a direct imaging with a direct approach (really paramedian) rather than the more lateral intercostal retrograde method.

For clarity, we have chosen to present the data for one patient (Patient 1) along with the successive steps (Figures 1-4), as a sort of acceptable example, rather than selecting the most perfect views at each step, because of the distinct anatomies among the patients (e.g., different thoracic or lumbar levels, different etiologies). Nevertheless, the quality of the individual data remains comparable and relatively good despite the local modifications and the limited capabilities of our workstation at that time.

Ultimately, the analysis of the individual imaging data, focusing on the control radiograph taken just after the injection through the catheter of the local anesthetic mixture with the contrast dye (Figure 4), reveals a linear and strictly ipsilateral infiltration of the PV area similar to previous radiographic studies $[13,14]$ and in agreement with the clinical analgesic effects (Table 2). In this context, we used the fluoroscopy in this series only to make more concrete the final result of the injection as a sort of validation of the imaging of the series. In our current practice we do not use it.

Even when it is uneventful, laminectomy leads to the complete loss of the anatomical structures, which are 
Placement in Patients with Laminectomy after Thoracotomy or Lumbotomy: A Case Series Imaging Study

Table 2. Summary of the surgery, block performance, and postoperative period (pain control) in the four patients.

\begin{tabular}{|c|c|c|c|c|c|c|c|c|}
\hline & \multirow[b]{2}{*}{$\begin{array}{c}\text { Surgery } \\
\\
\text { Vertebra* }^{*} \\
\text { Incision }^{* *} \\
\text { Anesthesia area }^{* * *}\end{array}$} & \multicolumn{3}{|c|}{ Block performance } & \multicolumn{4}{|c|}{ Postoperative period } \\
\hline & & $\begin{array}{l}\begin{array}{c}\text { Marking out } \\
(\text { min) })^{1}\end{array} \\
\text { Performance } \\
(\text { min })^{2} \\
\text { Attempt }^{3} \\
\text { number }^{3}\end{array}$ & $\begin{array}{l}\text { Depth of location } \\
\text { (cm) Catheter } \\
\text { placement: } \\
\text { Direction } \\
\text { (cranial, caudal) } \\
\text { Length }(\mathrm{cm}) \\
\text { US check } \\
\text { (yes/no) } \\
\text { X-ray check (level } \\
\text { up/down) })^{5}\end{array}$ & $\begin{array}{l} \\
\text { Initial local } \\
\text { anesthetic } \\
\text { mixture } \\
\text { injection } \\
\text { + Iodixanol } \\
\end{array}$ & $\begin{array}{c}\text { Continuous } \\
\text { infusion } \\
\text { Duration } \\
\text { Additional bolus }\end{array}$ & $\begin{array}{l}\text { Analgesia: } \\
\text { Systemic }^{10} \\
\left.\left(\mathrm{Yes}_{\mathrm{N}}\right)\right) \\
\text { Rescue }^{11} \\
(\mathrm{Yes} / \mathrm{No})\end{array}$ & $\begin{array}{c}\text { Visual analog } \\
\text { pain } 100 \mathrm{~mm} \\
\text { score } \\
\text { (before \& after } \\
\text { physiotherapy): } \\
\text { Day 1 } \\
\text { Day 2 } \\
\text { Day 3 }\end{array}$ & $\begin{array}{l}\text { Specific } \\
\text { chest pain at } \\
\text { the tube } \\
\text { drain } \\
\text { emergence } \\
\text { (Yes/No) }\end{array}$ \\
\hline Patient 1 & $\begin{array}{c}\text { T6-T7 } \\
{[\text { [T5-T8] }}\end{array}$ & $\begin{array}{c}12 \\
10 \\
2\end{array}$ & $\begin{array}{c}2.9 \mathrm{~cm} \mathrm{[T6]} \\
\text { Cranial } \\
3 \\
\text { Yes } \\
3 / 3\end{array}$ & $\begin{array}{l}\text { LIDO } 2 \% \\
\quad(5 \mathrm{ml}) \\
\text { ROPI } 0.5 \% \\
\quad(10 \mathrm{ml})\end{array}$ & $\begin{array}{c}\text { ROPI } 0.2 \% \\
\left(5-7 \mathrm{ml} \cdot \mathrm{h}^{-1}\right) \\
48 \mathrm{~h} \\
\text { LIDO } 1 \% \\
(5 \mathrm{ml})=3\end{array}$ & $\begin{array}{l}\text { Yes } \\
\text { Yes } \\
\text { (D1) }\end{array}$ & $\begin{array}{l}28 / 36 \\
25 / 30 \\
22 / 30\end{array}$ & No \\
\hline Patient 2 & T12-L1 & $\begin{array}{c}10 \\
10 \\
1\end{array}$ & $\begin{array}{c}3.4 \mathrm{~cm} \mathrm{[L1]} \\
\text { caudal } \\
3 \\
\mathrm{No} \\
2 / 3\end{array}$ & $\begin{array}{l}\text { LIDO } 2 \% \\
\quad(8 \mathrm{ml}) \\
\text { ROPI } 0.5 \% \\
\quad(8 \mathrm{ml})\end{array}$ & $\begin{array}{c}\text { ROPI } 0.2 \% \\
\left(7-9 \mathrm{ml}^{-1} \mathrm{~h}^{-1}\right) \\
72 \mathrm{~h} \\
\text { LIDO } 1 \% \\
(5 \mathrm{ml})=2\end{array}$ & $\begin{array}{l}\text { Yes } \\
\text { No }\end{array}$ & $\begin{array}{l}22 / 31 \\
20 / 34 \\
17 / 25\end{array}$ & No \\
\hline Patient 3 & $\begin{array}{c}\text { T7-T8 } \\
{[\text { T5-T9] }}\end{array}$ & $\begin{array}{c}12 \\
8 \\
2\end{array}$ & $\begin{array}{c}2.8 \mathrm{~cm}[\mathrm{~T} 7] \\
\text { Cranial } \\
2 \\
\text { Yes } \\
2 / 2\end{array}$ & $\begin{array}{l}\text { LIDO } 2 \% \\
\quad(5 \mathrm{ml}) \\
\text { ROPI } 0.5 \% \\
\quad(10 \mathrm{ml})\end{array}$ & $\begin{array}{c}\text { ROPI } 0.2 \% \\
\left(5-8 \mathrm{ml} \cdot \mathrm{h}^{-1}\right) \\
72 \mathrm{~h} \\
\text { LIDO } 1 \% \\
(5 \mathrm{ml})=2\end{array}$ & $\begin{array}{c}\text { Yes } \\
\text { Yes } \\
\text { (D1) }\end{array}$ & $\begin{array}{l}34 / 42 \\
28 / 35 \\
22 / 32\end{array}$ & Yes \\
\hline Patient 4 & & $\begin{array}{c}10 \\
8 \\
1\end{array}$ & $\begin{array}{c}9 \mathrm{~cm} \mathrm{[L3]} . \\
\text { Cranial } \\
3 \\
\text { Yes } \\
3 / 1\end{array}$ & $\begin{array}{l}\text { LIDO } 2 \% \\
\quad(6 \mathrm{ml}) \\
\text { ROPI } 0.5 \% \\
\quad(10 \mathrm{ml})\end{array}$ & $\begin{array}{c}\text { ROPI } 0.2 \% \\
\left(6-8 \mathrm{ml} \cdot \mathrm{h}^{-1}\right) \\
72 \mathrm{~h} \\
\text { LIDO } 1 \% \\
(5 \mathrm{ml})=3\end{array}$ & $\begin{array}{c}\text { Yes } \\
\text { Yes } \\
\text { (D1) }\end{array}$ & $\begin{array}{l}33 / 39 \\
28 / 35 \\
12 / 34\end{array}$ & $\mathrm{~N} / \mathrm{A}^{19}$ \\
\hline
\end{tabular}

"The operated pathological vertebra (as a black rectangle), first for laminectomy (posterior approach) and second for corporectomy with prosthetic replacement by an antero-lateral approach using a postero-lateral thoracotomy. ${ }^{* *}$ The level of the postero-lateral thoracotomy or lombotomy (as an oblique straight black line). ${ }^{* * *}$ The initial cutaneous area of anesthesia assessed by cold and pinprick tests just after the anesthesia at the arrival of the patient in the post-anesthesia care unit, before starting the continuous infusion.

replaced by an inhomogeneous tissue without any structures. Despite an extensive edematous process, the US examination nevertheless remains quite normal even just below the surgical site (Figures 2 and 3). Consequently, it was possible to perform a PV block relatively easily after a careful regional US analysis, illustrating the real strength of the USG approach. We also note some relevant similarities with previous data. First, we could infiltrate the PV area easily, but similar to the description of Luyet et al. [8], the catheter placement was difficult in only one patient (Patient 2), in which we needed to readjust the Tuohy needle. Otherwise, the respective depths of location were comparable to those already reported $[8,9]$, which is especially relevant for the series of Pusch et al. [9], whose patients were all female as in our series, while Riain et al. [6] reported having taken the same amount of time to perform PV blocks (between 8 and 10 minutes). The main difference is the duration of the preliminary localization needed under our specific conditions because of the deep local changes resulting from the laminectomy.

Thus, this series validates the interest in USG, showing that its relevance in successful performance of difficult blocks like these is indisputable. Moreover, in 


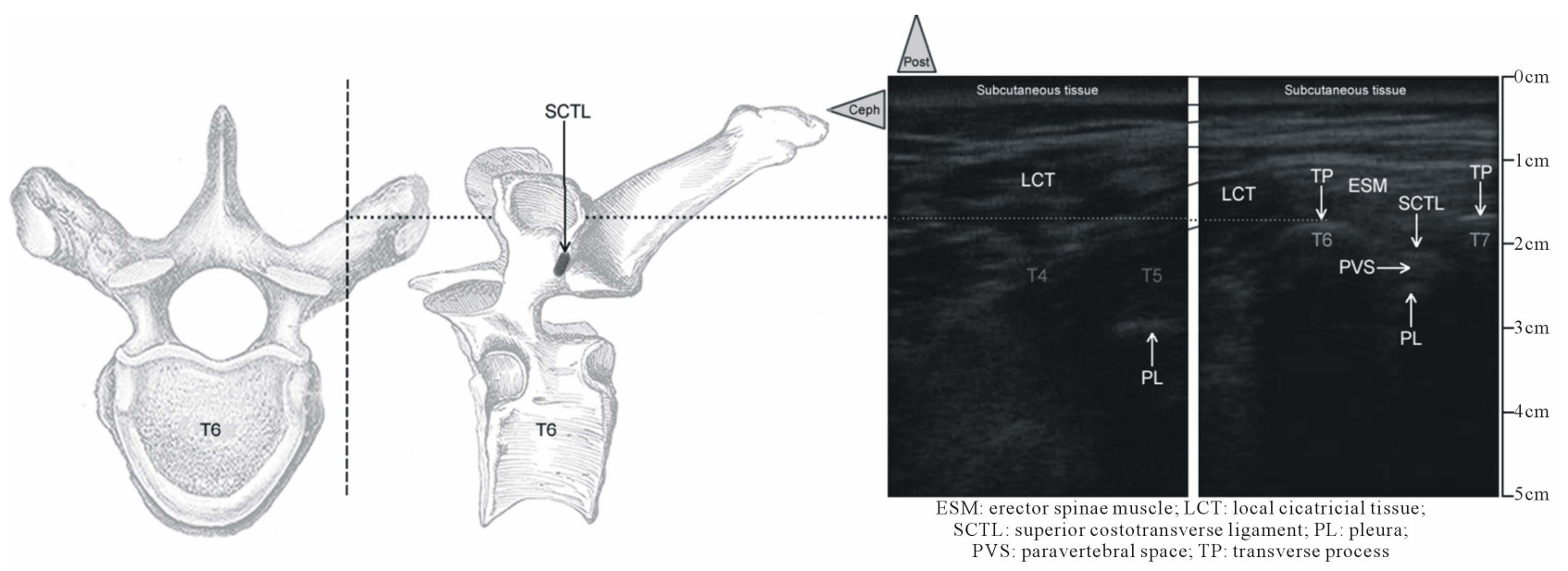

Figure 3. Long-axis ultrasound pinpointing before the needle insertion. In Patient 1 , the paramedian longitudinal sonograms of the right PV area with a 10 - $5 \mathrm{MHz} 38-\mathrm{mm}$ broadband linear array transducer (depth of $7 \mathrm{~cm})$ at, respectively, T4 and T5 (on left) and T6 and T7 (on right). Thin black lines show the continuity between the sonograms. Between T6 and T7, (on right), not only the erector spinae muscle is identifiable but also deeper the costotransverse ligament. The axial and sagittal anatomical views of a thoracic vertebra (on left) make easier, the sonograms reading (on right). On the axial view, the dashed vertical line shows plan of the longitudinal sonograms. These anatomical structures are progressively replaced by the inhomogeneous cicatricial tissue corresponding to the laminectomy previously performed in the patient using a posterior approach making difficult the usual pinpointing.

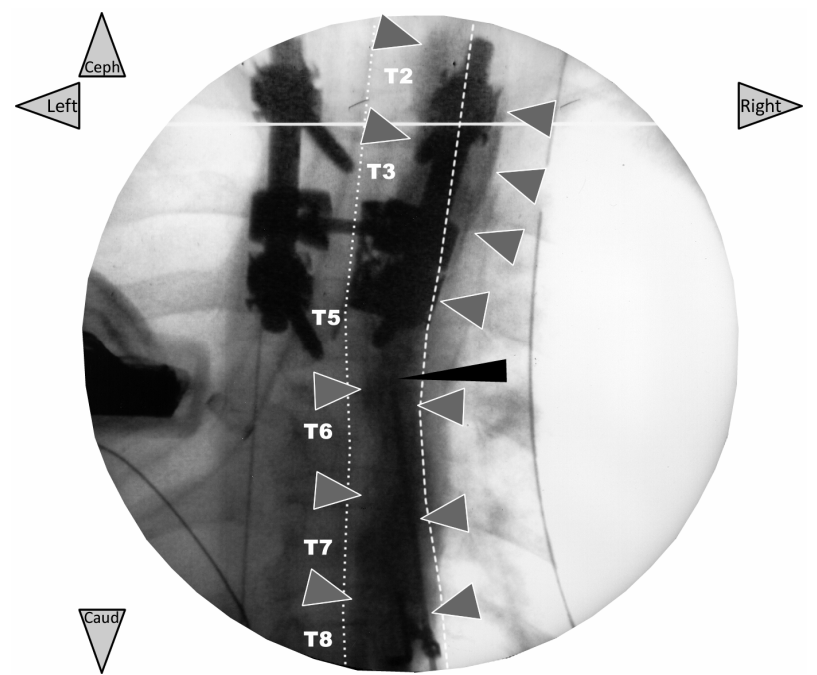

Figure 4. Frontal radiograph taken just after the initial injection of the local anesthetic mixture with iodixanol (only validation of the ultrasound-guided PV block technique). In patient 1 , the radiopaque dye $(2 \mathrm{ml}$ of iodixanol $320 \mathrm{mg}$ $\mathrm{ml}^{-1}$ ) added to the local anesthetic mixture $(5 \mathrm{ml}$ of $2 \%$ lidocaine $+10 \mathrm{ml}$ of $0.5 \%$ ropivacaine) shows that the mixture injected through the catheter (needle in place) has diffused along the right $P V$ area three levels above and below the needle-insertion point (grey arrows). There is no prevertebral or contralateral dye diffusion. The thin black arrow shows the Tuohy needle left in place for the injection through the polyethylene catheter inserted $3 \mathrm{~cm}$ over this tip. The needle was removed immediately, after.

accordance with the existing data $[6-8,11,12]$, and taking into account the specific local conditions of our patients, the USG has proved useful and necessary in the short term. The results in our four patients should add to the data suggesting a generalization of the US technique for this sort of regional anesthesia, making a practice that has been too often contra-indicated without USG possible and safe with relative certainty.

\section{Implications}

Paravertebral analgesia using a catheter, similar to the epidural technique, is a technique for postoperative pain control after thoraco-abdominal surgeries, including thoracotomy and the lumbotomy. For this procedure, anatomical parietal landmarks are of major importance because, for instance, of the proximity of the pleura and vessels. When the local structures are altered (e.g., by laminectomy), paravertebral block can be easier and safer to do using ultrasound guidance to make up for absent landmarks.

\section{REFERENCES}

[1] G. P. Joshi, F. Bonnet, R. Shah, et al., "A Systematic Review of Randomized Trials Evaluating Regional Techniques for Postthoracotomy Analgesia," Anesthesia \& Analgesia, Vol. 107, No. 3, 2008, pp. 1026-1040. doi:10.1213/01.ane.0000333274.63501.ff

[2] R. G. Davies, P. S. Myles and J. M. Graham, "A Comparison of the Analgesic Efficacy and Side-Effects of Paravertebral vs Epidural Blockade for Thoracotomy-A Systematic Review and Meta-Analysis of Randomized Trials," British Journal of Anesthesia, Vol. 96, No. 4, 2006, 
pp. 418-426. doi:10.1093/bja/ael020

[3] A. Kotzé, A. Scally and S. Howell, "Efficacy and Safety of Different Techniques of Paravertebral Block for Analgesia after Thoracotomy: A Systematic Review and Metaregression," British Journal of Anesthesia, Vol. 103, No. 5, 2009, pp. 626- 636. doi:10.1093/bja/aep272

[4] M. J. Eason and R. Wyatt, "Paravertebral Thoracic Block -A Reappraisal," Anaesthesia, Vol. 34, No. 7, 1979, pp. 638-642. doi:10.1111/j.1365-2044.1979.tb06363.x

[5] A. P. Boezaart, S. D. Lucas and C. E. Elliott, "Paravertebral Block: Cervical, Thoracic, Lumbar and Sacral," Current Opinion in Anaesthesiology, Vol. 22, No. 5, 2009, pp. 637-643. doi:10.1097/ACO.0b013e32832f3277

[6] O. Riain, B. O. Donnell, T. Cuffe, et al., "Thoracic Paravertebral Block Using Real-Time Ultrasound Guidance," Anesthesia \& Analgesia, Vol. 110, No. 1, 2010, pp. 248251. doi:10.1213/ANE.0b013e3181c35906

[7] A. Ben-Ari, M. Moreno, J. E. Chelly, et al., "UltrasoundGuided Paravertebral Block Using an Intercostal Approach," Anesthesia \& Analgesia, Vol. 109, No. 5, 2009, pp. 1691-1694. doi:10.1213/ANE.0b013e3181b72d50

[8] C. Luyet, U. Eichenberger, R. Greif, et al., "UltrasoundGuided Paravertebral Puncture and Placement of Catheters in Human Cadavers: An Imaging Study," British Journal of Anesthesia, Vol. 102, No. 4, 2009, pp. 534-539. doi:10.1093/bja/aep015
[9] F. Pusch, E. Wilding, W. Klimscha, et al., "Sonographic Measurement of Needle Insertion Depth in Paravertebral Blocks in Womem," British Journal of Anesthesia, Vol. 85, No. 6, 2000, pp. 841-843. doi:10.1093/bja/85.6.841

[10] L. Kirchmair, T. Entner, J. Wissel, et al., "A Study of the Paravertebral Anatomy for Ultrasound-Guided Posterior Lumbar Plexus Block," Anesthesia \& Analgesia, Vol. 93, No. 2, 2001, pp. 477-481.

[11] J. Richardson and P. A. Lonnqvist, "Thoracic Paravertebral Block," British Journal of Anesthesia, Vol. 81, No. 2, 1998, pp. 230-238. doi:10.1093/bja/81.2.230

[12] D. A. Burns, B. Ben-David, J. E. Chelly, et al., "Intercostally Placed Paravertebral Catheterization: An Alternative Approach to Continuous Paravertebral Blockade," Anesthesia \& Analgesia, Vol. 107, No. 1, 2008, pp. 339-341. doi:10.1213/ane.0b013e318174dfld

[13] G. Purcell-Jones, C. E. Pither and D. M. Justins, "Paravertebral Somatic Nerve Block: A Clinical, Radiographic and Computed Tomographic Study in Chronic Pain Patients," Anesthesia \& Analgesia, Vol. 68, No. 1, 1989, pp. 32-39. doi:10.1213/00000539-198901000-00008

[14] I. D. Conacher and M. Kokri, "Postoperative Paravertebral Blocks for Thoracic Surgery. A Radiological Appraisal," British Journal of Anesthesia, Vol. 59, No. 2, 1987, pp. 155-161. doi:10.1093/bja/59.2.155 